\title{
Homologues of the Cf-9 Disease Resistance Gene (Hcr9s) Are Present at Multiple Loci on the Short Arm of Tomato Chromosome 1
}

\author{
Martin Parniske, ${ }^{1}$ Brande B. H. Wulff, ${ }^{1}$ Guusje Bonnema, ${ }^{2}$ Colwyn M. Thomas, ${ }^{1}$ David A. Jones, ${ }^{1}$ and \\ Jonathan D. G. Jones ${ }^{1}$ \\ ${ }^{1}$ The Sainsbury Laboratory, John Innes Centre, Colney Lane, Norwich NR4 7UH, U.K.; ${ }^{2}$ Department \\ of Molecular Biology, Dreijenlaan 3, Wageningen Agricultural University, 6703HA Wageningen, \\ The Netherlands \\ Accepted 30 October 1998.
}

\begin{abstract}
The tomato $C f-4$ and $C f-9$ genes map at a genetically complex locus on the short arm of chromosome 1 and confer resistance against Cladosporium fulvum through recognition of different pathogen-encoded avirulence determinants. $C f-4$ and $C f-9$ are members of a large gene family (Hcr9s, Homologues of Cladosporium fulvum resistance gene $C f-\underline{9}$ ), some of which encode additional distinct recognition specificities. A genetic analysis of the majority of Hcr9s suggests that their distribution is spatially restricted to the short arm of chromosome 1. Two loci of clustered Hcr 9 genes have been analyzed physically that mapped distal (Northern Lights) and proximal (Southern Cross) to the $C f-4 / 9$ locus (Milky Way). Sequence homologies between intergenic regions at Southern Cross and Milky Way indicate local $\mathrm{Hcr} 9$ duplication preceded cluster multiplication. The multiplication of clusters involved DNA flanking $\mathrm{Hcr} 9$ sequences as indicated by conserved lipoxygenase sequences at Southern Cross and Milky Way. The similar spatial distribution of $\mathrm{Hcr} 9$ clusters in different Lycopersicon spp. suggests Hcr9 cluster multiplication preceded speciation.
\end{abstract}

Plants possess a powerful arsenal of defense mechanisms to inhibit the growth of fungal, bacterial, viral, insect, and nematode pathogens. Many of these require induction following recognition of the pathogen by the plant. In many plant-pathogen interactions resistance is specified by a genefor-gene relationship in which the recognition of pathogenencoded avirulence $(A v r)$ genes is mediated by plant resistance $(R)$ genes, consistent with a model in which the $\mathrm{R}$ protein constitutes a receptor that specifically interacts with the corresponding Avr protein (for a review see Hammond-

Corresponding author: Jonathan D. G. Jones; Telephone: +44-1603452571; Fax: +44-1603-250024; E-mail: jonathan.jones@bbsrc.ac.uk

Present address of Guusje Bonnema: Department of Plant Breeding, Wageningen Agricultural University, Postbox 387, 6700 AJ Wageningen, The Netherlands.

Present address of David A. Jones: Research School of Biological Sciences, Australian National University, P.O. Box 475, Canberra ACT 2601, Australia.
Kosack and Jones 1997). Physical interaction between the product of the tomato Pto gene, a protein kinase, and the cognate Avr protein AvrPto from Pseudomonas syringae pv. tomato could be detected with a yeast two hybrid assay (Scofield et al. 1996; Tang et al. 1996). Several different classes of $R$ genes have been described and some are members of tightly linked, multigene families (Anderson et al. 1997; Salmeron et al. 1996; Simons et al. 1998; Song et al. 1997). In several species molecular analysis has shown that large and often clustered families of $R$ gene homologues cosegregate with different resistance specificities (Botella et al. 1997; Collins et al. 1998; Leister et al. 1996). In cases in which different resistances are mediated by homologous $R$ genes, it will be interesting to determine the evolutionary mechanisms that generate novel recognition specificities.

One of the most advanced pathosystems for the study of the interaction between $R$ and $A v r$ genes is resistance in tomato against the leaf mold fungus Cladosporium fulvum. Tomato $\mathrm{Cf}$ proteins are predicted membrane-bound proteins consisting of extracellular leucine-rich-repeats (LRRs) (Dixon et al. 1996, 1998; Jones et al. 1994; Thomas et al. 1997). As LRRs have been implicated in protein-protein interactions (Kobe and Deisenhofer 1995), their presence is compatible with the Cf proteins functioning as receptors for fungal-encoded Avr peptides. The fungal avirulence genes Avr4 (Joosten et al. 1994) and $A v r 9$ (Van Kan et al. 1991) encode small, cysteine-rich peptides secreted by the fungus, and confer avirulence on tomato plants expressing the resistance genes $C f-4$ or $C f-9$, respectively. However, no direct physical interaction between Cf-4 and Avr4 or Cf-9 and Avr9 has yet been demonstrated.

$C f-4$ and $C f-9$ belong to a large gene family (Hcr $9 \mathrm{~s}$;

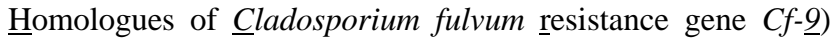
and map to a complex locus on the short arm of chromosome 1, consisting of clustered Hcr9 genes (Parniske et al. 1997; Thomas et al. 1997). Additional resistance specificities, for example $C f-1$ (Kerr and Bailey 1964), have been mapped closely linked to $C f-4 / 9$ (Jones et al. 1993; Laugé et al. 1998). The benefit of studying the tomato/C. fulvum interaction to understand the molecular basis for pathogen recognition lies in the availability of a growing number of specific pairs of avirulence peptides and cognate Hcr9s. $H c r 9 s$ at the $C f-4 / 9$ locus, in addition to $C f-4$ and $C f-9$, have been shown to en- 
code resistance to $C$. fulvum, by the recognition of avirulence determinants other than Avr4 and Avr9 (Parniske et al. 1997).

We are interested in determining the molecular mechanisms that generate $\mathrm{Hcr} 9$ sequence variants that potentially encode novel recognition specificities. We have therefore started a detailed molecular analysis of the $H c r 9$ gene family. Here we present refined mapping data of $H c r 9 \mathrm{~s}$ that are present not only at the $C f-4 / 9$ locus but also at distinct, genetically linked loci. Bonnema et al. (1996) isolated yeast artificial chromosome (YAC) clones harboring Hcr9s. Several of these YACs were mapped to positions linked to the $C f-4 / 9$ locus. To complete our analysis of the Hcr9 gene family we want to examine the extent to which and mechanisms by which these additional $\mathrm{Hcr} 9$ loci participate in the evolution of the gene family. As a preliminary step we have genetically mapped these additional Hcr9 genes and shown that they are located at several loci on the short arm of tomato chromosome 1 . Three major clusters of tandemly arranged genes were identified. Physical contigs have been established for two of the Hcr9 loci that map proximal and distal to the $C f-4 / 9$ locus.

\section{RESULTS}

\section{Multiple Hcr9 loci on the short arm of tomato chromosome 1.}

Multiple Hcr9 genes in L. pennellii and the L. esculentum near isogenic lines (NILs) Cf0, Cf4, and Cf9 (Tigchelaar 1984) have been revealed by DNA gel blot analysis with a $C f$ 9 probe (Jones et al. 1994; Thomas et al. 1997). Seven different populations were used to map individual $\mathrm{Hcr} 9 \mathrm{~s}$ (see Materials and Methods). All Hcr9s that could be reliably scored were located on the short arm of chromosome 1 (Figures 1 and 2). Physical linkage of $\mathrm{Hcr} 9 \mathrm{~s}$ at three loci was confirmed by the analysis of YAC, phage, and cosmid contigs (see below). These loci were designated Southern Cross (SC), Milky Way $(M W)$, and Northern Lights $(N L)$. The nomenclature for Hcr9s derived from the $S C$ and $N L$ loci includes the locus and line of origin as well as the relative position in the cluster, e.g., Hcr9$S C O A$ (shorthand SCOA) refers to the first gene in the $\underline{S C}$ cluster originating from $\mathrm{Cf} \underline{0}$. Hcr 9 pseudogenes are prefixed by a $\Psi$. Gene nomenclature for the $C f-4 / 9$ locus has been described previously (Parniske et al. 1997; Thomas et al. 1997).

\section{The $C f-4 / 9$ locus (Milky Way).}

$C f-4$ and $C f-9$ are present in two distinct haplotypes in the NILs Cf4 and Cf9, respectively (Balint-Kurti et al. 1994; Jones et al. 1993; Parniske et al. 1997; Thomas et al. 1997). In order to identify $\mathrm{Hcr} 9 \mathrm{~s}$ from the corresponding locus in the disease susceptible line ( $\mathrm{Cf} 0$ ), recombination events between the T-DNA marker FT33 (Rommens et al. 1992) and the RFLP (restriction fragment length polymorphism) marker $\mathrm{CP} 46$ that flank the $C f-4 / 9$ locus were identified in $\mathrm{F}_{2}$ progeny from the crosses Cf0 FT33 $\times$ Cf4 or Cf0 FT33 $\times$ Cf9 $($ see Materials and Methods). Plants homozygous for the recombinant chromosome were then selected from $\mathrm{F}_{3}$ progeny. Since the $C f-4 / 9$ locus is located within the FT33/CP46 interval, the recombinants identified may or may not have contained $C f-4$ or $C f-9$. The presence of $C f-4$ or $C f-9$ was determined by both DNA gel blot analysis and crossing recombinant plants to transgenic Cf0 plants expressing either Avr4 or Avr9 to test for the seedling lethal phenotype (Hammond-Kosack et al. 1994a; Thomas et al. 1997). The results of both types of analysis were consistent (Fig. 3).

A single $B g l \mathrm{II}$ fragment of $3.4 \mathrm{~kb}$ hybridizing to $C f-9$ probe 1 (Jones et al. 1994) was linked in repulsion to $C f-4$ or $C f-9$ in the recombinants as revealed by DNA gel blot analysis (Fig. 3). A phage clone containing the 3.4-kb BglII fragment was isolated from a phage library of $L$. esculentum CfO genomic DNA. Analysis of this phage revealed that $\mathrm{Hcr} 9-\mathrm{O}$ resides on a 7.4-kb BamHI fragment linked in repulsion in the $\mathrm{F}_{3} \mathrm{FT} 4$ and $\mathrm{F}_{3} \mathrm{FT} 9$ recombinants to large Bam $\mathrm{HI}$ fragments containing either $C f-4$ or $C f-9$ (Fig. 3). The DNA sequence analysis of this phage clone has been reported previously (Parniske et al. 1997).

\section{Southern Cross.}

An $H c r 9$ gene cluster located proximal to $M W$ was named Southern Cross (SC; see Figure 1). Its presence was revealed

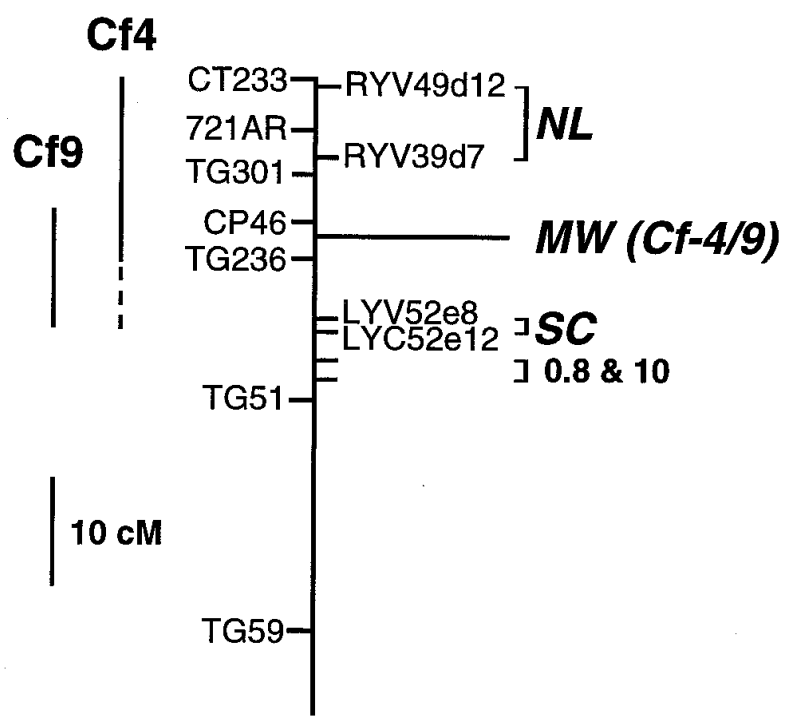

Fig. 1. Genetic mapping of the Hcr9 clusters Northern Lights (NL), Milky Way (MW), and Southern Cross (SC) on the short arm of tomato chromosome 1. Mapping distances were calculated by JoinMap incorporating data obtained from seven independent mapping populations (see Materials and Methods). RYV49d12 derived from the right end of yeast artificial chromosome (YAC) V49d12 (Bonnema et al. 1996) and RYV39d7 derived from the right end of YAC V39d7 (Bonnema et al. 1996) indicate markers derived from YAC ends physically delimiting the $N L$ cluster. LYV52e8 derived from the left end of YAC V52e8 (Bonnema et al. 1996) and LYC52e12 derived from the left end of YAC C52e12 (Bonnema et al. 1996) are markers physically delimiting the $S C$ cluster. 0.8 and 10 indicate positions of two cosegregating $B g I I I$ fragments of 0.8 and $10 \mathrm{~kb}$ from Lycopersicon esculentum that hybridize to $C f-9$ probe 1 and are located proximal to $S C$. Extent of introgressed DNA segments originating from L. hirsutum (Cf4) and L. pimpinellifolium (Cf9) in L. esculentum cv. Moneymaker (Cf0) are indicated as deduced from RFLP (restriction fragment length polymorphism) analysis in both this and an earlier study (Balint-Kurti et al. 1994). The most proximal marker polymorphic between Cf9 and Cf0 is a Cf9-specific, 2.1-kb BglII fragment hybridizing to Cf-9 probe 1 that maps to $S C$. Markers CT233, TG301, TG236, TG51, and TG59 have been described previously (Tanksley et al. 1992). JoinMap placed marker 721AR between RYV49d12 and RYV39d7, within a region physically covered by the $N L$ YAC contig; however, this has not been verified by hybridization analysis of the YAC clones. Marker FT33 maps to the "TG236 cluster," a region of reduced recombination in $F_{2}$ populations of crosses between L. esculentum and L. pennellii (Bonnema et al. 1997; Rommens et al. 1992; Tanksley et al. 1992). 
by a $2.1-\mathrm{kb} B g l \mathrm{II}$ fragment hybridizing to $C f-9$ probe 1 unique to the Cf9 line ("SC9" in Figure 2 and asterisk in Figure 3). This fragment cosegregated with TG236 or FT33 in the $\mathrm{F}_{2} \mathrm{P} 9 \mathrm{rec}$ and $\mathrm{F}_{3} \mathrm{FT} 9$ populations, respectively. In $62 \mathrm{~F}_{2} \mathrm{P} 9 \mathrm{~S}$ plants, four chromosomes recombinant between this fragment and TG236 were identified that placed $S C$ proximal to TG236 (percentage recombination $2.4 \pm 1.4 \%$ ). This fragment is absent in the CfO line, which indicates the $S C$ locus is polymorphic between Cf9 and Cf0. Therefore, the DNA segment in the Cf9 line introgressed from $L$. pimpinellifolium extends at least as far as $S C$ (Fig. 1 and 2).

A cosegregating dominant PCR (polymerase chain reaction) marker based on the $C f-9$ sequence was instrumental in the identification of phage clones corresponding to $S C$. The primers GBF2 and GBR4 when used to amplify DNA from the NILs Cf0, Cf4, or Cf9 gave a fragment of approximately 950 bp consistent with the Hcr9 consensus distance between the primer positions. In addition, a smaller product of $658 \mathrm{bp}$ was observed in the NILs but not in L. pennellii. This polymorphic fragment cosegregated with the $S C$-specific, 2.1-kb $B g l I I$ fragment in the $\mathrm{F}_{2} \mathrm{P} 9 \mathrm{rec}$ and $\mathrm{F}_{2} \mathrm{P} 9 \mathrm{~S}$ populations. The $\mathrm{Hcr} 9$ from which the fragment was obtained was contained within a phage contig carrying two Hcr9s (Fig. 4). No additional homology to $C f-9$ was detected on the contig by gel blot analysis. Contiguous DNA (11.2 kb) encompassing these two Hcr9s was sequenced $(S C O A$ and $\psi S C O B)$. Sequence analysis revealed that $\psi S C O B$ carried a deletion of 299 bp relative to $C f$ 9 starting at position +535 that accounted for the $658 \mathrm{bp}$, gene-specific PCR product described above. This deletion introduces a frameshift mutation. A single base pair insertion at position +2053 introduces a second frameshift. $\psi S C O B$ is therefore predicted to be a nonfunctional gene. In contrast, the SCOA gene carries an intact open reading frame and could therefore be functional.

The DNA sequence of the ends of two subclones extending 1.3 and $3.9 \mathrm{~kb}$ beyond the $3^{\prime}$ end of $\psi S C O B$ was determined ("A" and "B" in Figure 4B). The sequence 3 ' to $\psi S C O B$ ("A" in Figure 4B) was nearly identical over 183 bp to an insertion found in a mutant allele of a tomato phytoene synthase gene (Fray and Grierson 1993). This sequence has multiple copies in tomato and was therefore suggested to be part of a transposable element (Fray and Grierson 1993). This idea is further supported by the finding that the more distal sequence ("B" in Figure 4B) conceptually encodes a peptide with homology to a retroviral polyprotein encoded by $T n t-1$ of tobacco.

Two YACs, possibly harboring $H c r 9 s$, one originating from Cf4 and one from VFNT Cherry genomic libraries, were previously mapped to a position similar to $S C$ (Bonnema et al. 1996). We therefore compared these YACs with the CfO SC locus and identified identical restriction fragments within the region of Hcr 9 homology, which suggests that these clones represent the same locus of different cultivars. DNA gel blots of both YACs revealed $B g l \mathrm{II}$ fragments hybridizing to $C f-9$ probe 1 of 2.5 and $2.8 \mathrm{~kb}$, identical in size to fragments corresponding to $S C O A$ and $\psi S C O B$ (not shown). Furthermore, the 658-bp $\psi S C O B$ gene-specific PCR product was amplified with these YACs as templates. Two contiguous MluI fragments, of $6.1 \mathrm{~kb}$ and approximately $8 \mathrm{~kb}$, within the YAC clones hybridized to $C f-9$ probe 1 and their position relative to each other could be determined by DNA gel blot analysis of partially digested YAC DNA (not shown). The 6.1-kb fragment was contained within the sequenced region of the Cf0-derived phage contig. Only sequences distal to this $M l u I$ fragment are homologous to $C f-9$ probe 1 ; therefore, the 8 -kb $M l u I$ fragment has to be located distal to the 6.1-kb MluI fragment (Fig. 4). From this hybridization pattern, the orientation of the phage contig relative to the YAC clones, and consequently their chromosomal polarity, could be deduced. YACs YC52e12 and YV52e8, originating from Cf4 and VFNT Cherry, respectively, have different restriction maps proximal to the region in which Cf-9 homology was detected, indicating polymorphism between these two non-isogenic lines. However, no additional homology to Cf-9 was detected on the YAC clones, suggesting that the $S C$ locus in VFNT and Cf4 contains only two Hcr9s.

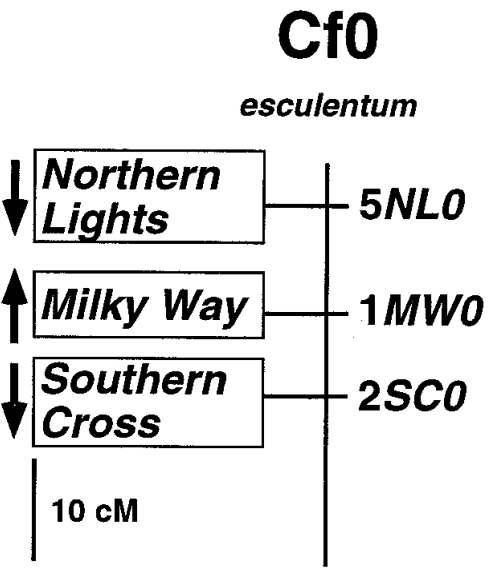

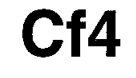

\section{hirsutum}

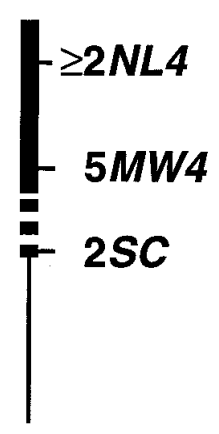

Cf9

pimpinellifolium

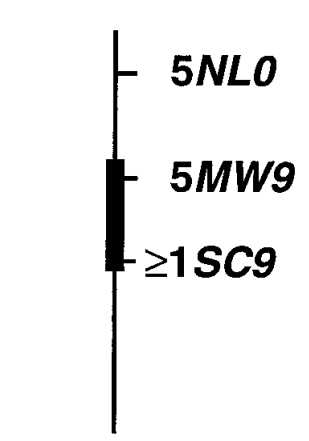

\section{VFNT}

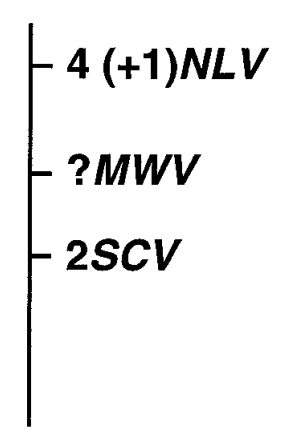

Fig. 2. Hcr 9 distribution on the short arm of chromosome 1 of four Lycopersicon esculentum cultivars. Distal regions of tomato chromosome 1 in the near isogenic lines Cf0, Cf4, and Cf9 as well as the cultivar VFNT Cherry are displayed together with the map positions of the Hcr9 clusters Northern Lights (NL), Milky Way (MW), and Southern Cross (SC) (left). The number of Hcr9s at each locus is indicated for each cultivar. Minimal numbers are given for $N L 4 \mathrm{~s}$ and $S C 9 \mathrm{~s}$ as deduced from genomic DNA gel blots, as no physical data are available. At $N L V$ the proximal physically separated $H c r 9$ (see Figure 6) is represented by (+1). Extent of the introgressed segment in the Cf4 and Cf9 lines is indicated by thick vertical lines (compare with Figure 1). Whether the $S C$ haplotype in the Cf4 line is part of the L. hirsutum introgression or alternatively is of L. esculentum (Cf0) origin was not determined. Arrows (left) indicate transcriptional orientation of $H c r 9 \mathrm{~s}$ within different clusters. Although all $H c r 9 \mathrm{~s}$ within a single cluster are transcribed in the same direction, the polarity of $M W$ is inverted relative to $S C$ and $N L$. 
The presence of an additional locus of $H c r 9$ genes proximal to $S C$ was suggested by two cosegregating $B g l$ II fragments of 0.8 and $10 \mathrm{~kb}$ that hybridized to $C f-9$ probe 1 in genomic DNA of Cf0, Cf4, and Cf9 but not in L. pennellii. (0.8 and 10 $\mathrm{kb}$ in Figure 1). These fragments mapped proximal to TG236 in the $\mathrm{F}_{2} \mathrm{P} 9 \mathrm{rec}, \mathrm{F}_{2} \mathrm{P} 9 \mathrm{~S}$, and $\mathrm{F}_{2} \mathrm{EP}$ populations (Fig. 1). They were separated from $S C$ by 2,11, and 2 recombination events in the $\mathrm{F}_{2} \mathrm{P} 9 \mathrm{rec}, \mathrm{F}_{2} \mathrm{P} 9 \mathrm{~S}$, and $\mathrm{F}_{2} \mathrm{EP}$ populations, respectively. In the $\mathrm{F}_{2} \mathrm{P} 4 \mathrm{rec}$ population only the $10-\mathrm{kb}$ fragment could be scored and shown to cosegregate with TG236. As fragments

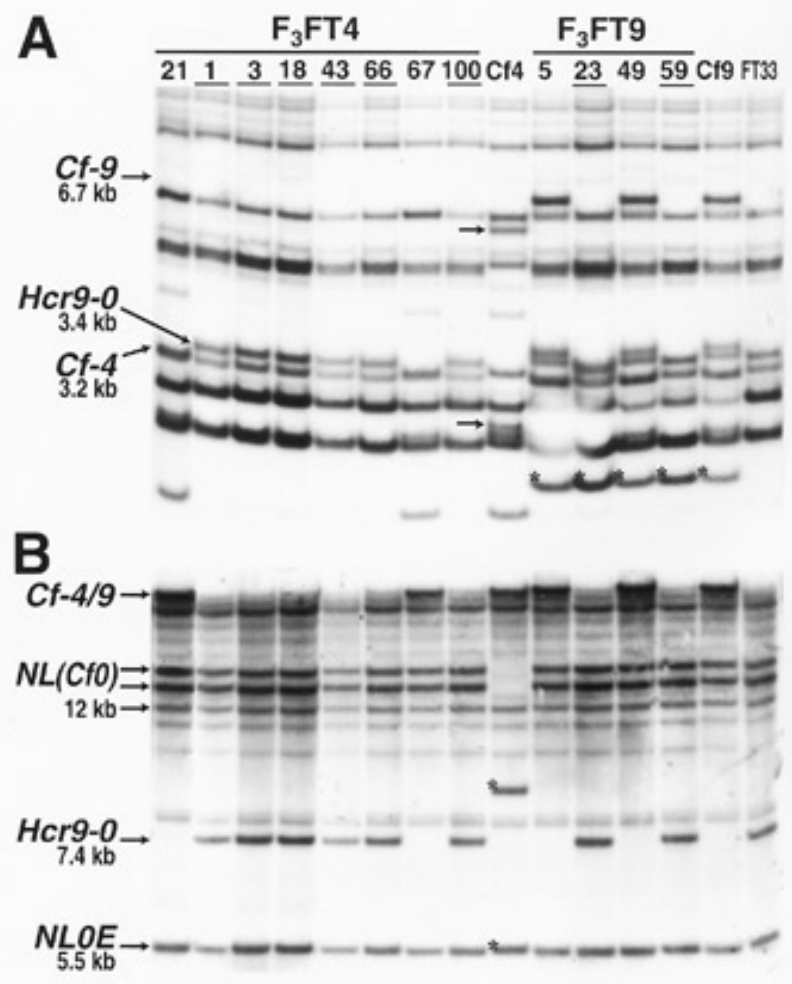

Fig. 3. DNA gel blot analysis of $\mathrm{F}_{3} \mathrm{FT} 4$ and $\mathrm{F}_{3} \mathrm{FT} 9$ recombinants. DNA gel blots of $\mathrm{F}_{3}$ plants homozygous for the recombinant chromosome probed with $C f-9$ probe 1 . Numbers on top identify individual recombinants. $\mathrm{F}_{3}$ individuals lacking $C f-4$ or $C f-9$ are underlined. $\mathbf{A}$, Gel blot of BglII-digested DNA. A 3.4-kb fragment (Hcr9-0 $3.4 \mathrm{~kb}$ ) from Cf0 FT33 (FT33) is linked in repulsion to a 3.2-kb fragment representing the $C f-4$ gene in the $\mathrm{F}_{3} \mathrm{FT} 4$ population $(C f-43.2-\mathrm{kb})$ or a $6.7-\mathrm{kb}$ fragment representing the $C f-9$ gene in the $\mathrm{F}_{3} \mathrm{FT} 9$ population $(C f-96.7 \mathrm{~kb})$. The $3.4-\mathrm{kb}$ fragment therefore corresponds to the Lycopersicon esculentum allele of the $C f-4 / 9$ locus. The 2.1-kb Cf9-specific fragment located at Southern Cross (SC) is labeled with asterisks. Fragments of 5.9 and $2.6 \mathrm{~kb}$ in the Cf4 line are labeled with arrows. The 5.9-kb fragment is located distal to $\mathrm{CP} 46$; the 2.6-kb fragment cosegregates with $\mathrm{CP} 46$ in the $\mathrm{F}_{2} \mathrm{P} 4 \mathrm{rec}$ population. B, Gel blot of BamHI-digested DNA. A 7.4-kb fragment present in Cf0 FT33 is linked in repulsion to a BamHI fragment of $>37$ kb carrying the entire $C f-4$ cluster ( $C f-4$ in 21,67 , and Cf4) or $40.6 \mathrm{~kb}$ carrying the entire $C f-9$ cluster ( $C f-9$ in 5, 49, and Cf9). This fragment therefore corresponds to the L. esculentum allele of the $C f-4 / 9$ locus. Sequence analysis has revealed the presence of a single Hcr9 on this fragment (Hcr9-0) (Parniske et al. 1997). Two fragments of 13.6 and $15.2 \mathrm{~kb}$ from Cf0 FT33 are absent in Cf4 $(N L(C f O))$. Together with a 5.5 -kb fragment $(N L O E)$ they represent the L. esculentum $N L$ cluster (Fig. 6). Northern Lights (NL) of Cf4 and L. esculentum are polymorphic. Two fragments of 5.5 and $8.5 \mathrm{~kb}$ (marked with an asterisk in Cf4) are linked to $N L$ and represent $L$. hirsutum DNA. $N L$ of Cf9 and $L$. esculentum are nonpolymorphic. Therefore, the Cf9 line probably carries L. esculentum DNA at $N L$. of 0.8 or $10 \mathrm{~kb}$ were absent from the $S C$ phage contig and the $S C$ YACs (Fig. 4), this additional $\mathrm{Hcr} 9$ cluster must be located at least $200 \mathrm{~kb}$ proximal to $S C$ (Fig. 2).

Four $B g l$ II fragments of $8.1,4.0,3.9$, and $1.1 \mathrm{~kb}$ from $L$. pennellii that hybridized to $C f-9$ probe 1 were found to be absolutely linked in the $\mathrm{F}_{2} \mathrm{EP}$ population, suggesting the presence of an $\mathrm{Hcr} 9$ gene cluster in this species. An additional single fragment of $7.9 \mathrm{~kb}$ was closely linked. This cluster and the linked fragment also mapped proximal to TG236. A larger mapping population that would allow higher resolution mapping of these $H c r 9 \mathrm{~s}$ would be required to establish allelism between L. pennellii and L. esculentum Hcr9 loci. However, assuming synteny between different Lycopersicon spp., the $L$. pennellii Hcr $9 \mathrm{~s}$ described are likely to originate from the $L$. pennellii haplotypes of the proximal Hcr9 loci.

\section{Genetic and physical mapping of $N L$.}

The $N L$ locus was identified by two cosegregating BglII fragments present in $\mathrm{CfO}$ and $\mathrm{Cf} 9$ of 3.0 and $3.2 \mathrm{~kb}$ that hybridized to $C f-9$ probe 1 . These fragments mapped distal to $\mathrm{CP} 46$ in the $\mathrm{F}_{2} \mathrm{EP}, \mathrm{F}_{2} \mathrm{P} 9 \mathrm{~S}, \mathrm{~F}_{2} \mathrm{P} 9 \mathrm{rec}$, and $\mathrm{F}_{3} \mathrm{FT} 4$ populations.

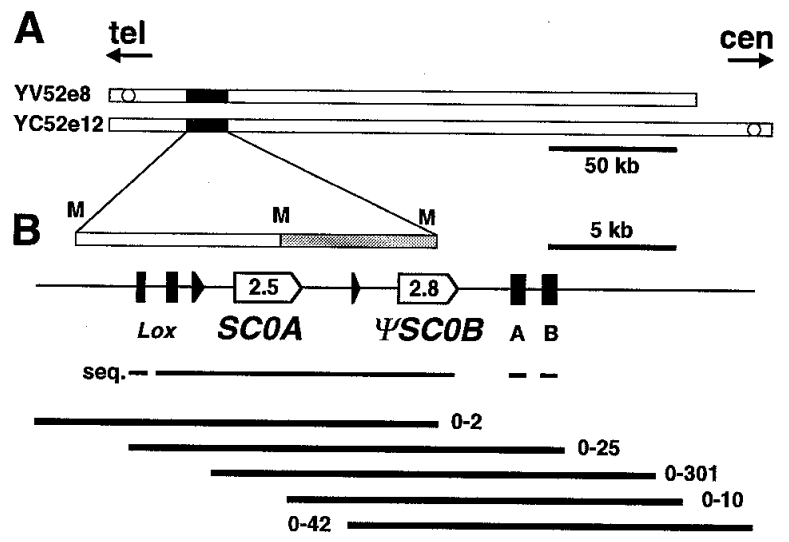

Fig. 4. Physical map of the Southern Cross (SC) locus from Cf0. A, SCYAC contig. Insert sizes and positions of two yeast artificial chromosome (YAC) clones carrying VFNT Cherry genomic DNA (YV52e8) or Cf4 genomic DNA (YC52e12) are indicated by two hollow bars (Bonnema et al. 1996). The two YACs exhibit restriction fragment length polymorphism, probably a reflection of the polymorphism between Cf4 and VFNT Cherry in this region. Orientation of these YACs relative to the telomere (tel) and centromere (cen) has been determined by mapping of markers derived from left YAC ends (hollow circles) (Bonnema et al. 1996). They are assumed to map to corresponding regions of both genomes because the left YAC ends of both clones map very close to each other and both clones contain two similar and contiguous $M l u \mathrm{I}$ fragments hybridizing to $C f-9$ probe 1 . Hybridizing region is indicated by black bars. The two $M l u \mathrm{I}$ fragments are shown enlarged above the phage contig linking the YACs with the phage contig. A 6.1$\mathrm{kb} M l u \mathrm{I}$ fragment present in the sequenced region of the Cf0 phage contig is highlighted in gray. B, SC phage contig. Physical extent of individual overlapping phage clones isolated from the Cf0 line is shown by solid bars. Extent of sequenced regions is indicated by solid lines (seq.). Hollow arrows indicate position of $\mathrm{Hcr} 9 \mathrm{~s}$, including size $(\mathrm{kb})$ of corresponding $B g l I$ fragment hybridizing to $C f-9$ probe 1 . Filled boxes and triangles $5^{\prime}$ of $S C O A$ indicate position of exons of a lipoxygenase gene (Lox) highly homologous to the Lox gene located $5^{\prime}$ of the $C f-4 / 9$ locus (Parniske et al. 1997). Triangle between SCOA and $\Psi S C O B$ indicates position of a truncated fragment of the $3^{\prime}$ most exon of Lox. Sequenced regions $3^{\prime}$ of $\Psi S C O B$ (A and B) suggest presence of a retrotransposon (see text for details). Size of $S C O$ cluster is $8.7 \mathrm{~kb}$ (ATG transcriptional start codon of $S C O A$ to stop codon of $\Psi S C O B$ ). 
Inspection of the $\mathrm{F}_{2} \mathrm{EP}$ and $\mathrm{F}_{3} \mathrm{FT} 4$ populations revealed close linkage to RFLP marker 721AR (Thomas et al. 1994; Fig. 1). No fragments cosegregating with $N L$ were detected that were polymorphic between $\mathrm{CfO}$ and $\mathrm{Cf} 9$ in gel blots of BamHI- or $B g l$ II-digested genomic DNA hybridized to $C f$ - 9 probe 1 , suggesting similar or identical $N L$ haplotypes in these NILs. It is therefore likely that the L. pimpinellifolium introgression in Cf9 does not extend as far as $N L$, consistent with a previous report that placed 721AR outside the region of introgressed $L$. pimpinellifolium DNA (Balint-Kurti et al. 1995; Fig. 1).

A YAC contig of L. esculentum VFNT Cherry DNA containing $\mathrm{Hcr} 9 \mathrm{~s}$ was previously mapped to a position similar to $N L$ (Bonnema et al. 1996; Fig. 1). BglII fragments of 3.0 and $3.2 \mathrm{~kb}$, characteristic of the Cf0 and Cf9 $N L$ haplotypes, as well as three additional fragments hybridizing to $C f-9$ probe 1, were contained within this contig (Fig. 5). Physical mapping of the VFNT Cherry YAC contig defined two regions of 27.4 and $40 \mathrm{~kb}$, separated by $52 \mathrm{~kb}$, that contained four and one Hcr9 $\mathrm{Bg}$ III fragments, respectively (Fig. 6). This suggests the presence of a tightly linked cluster of four Hcr 9 s and an additional, physically separated single Hcr9. These clusters have also been resolved genetically in the $\mathrm{F}_{2}$ EPwag population (Fig. 6; and data not shown). The clustered $H c r 9$ s were represented by $B g l \mathrm{II}$ fragments of 4.9 , $3.2,3.0$, and $2.4 \mathrm{~kb}$.

Clones containing both the 3.0- and 3.2-kb fragments were isolated from a Cf0 phage library (Figs. 5 and 6) and assembled into a contig. Additional clones harboring these fragments were isolated from a Cf2/9 cosmid library but not characterized further. A second $\mathrm{Cf0}$ phage contig consisting of four clones contained the 4.9- and 2.4-kb BglII fragments (Figs. 5 and 6).

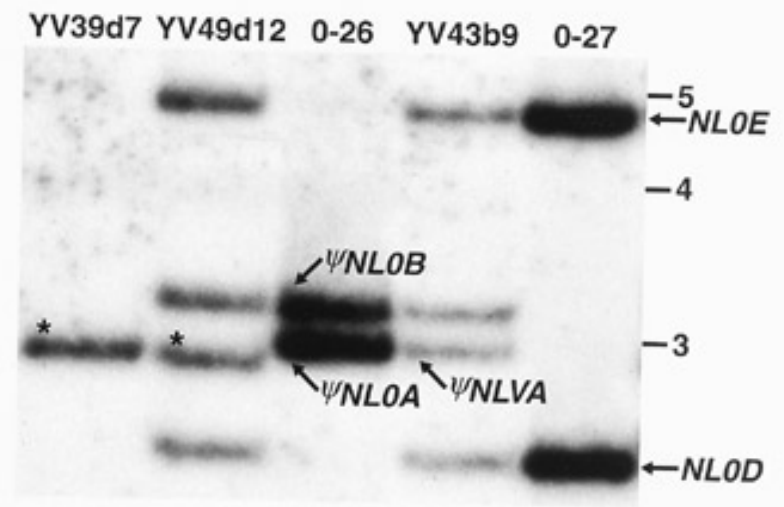

Fig. 5. Comparison of Northern Lights (NL) yeast artificial chromosome (YAC) and phage clones. Gel blot of BglII-digested yeast (YV39d7, YV49d12, YV43b9) or phage (0-26, 0-27) DNA hybridized with $C f-9$ probe 1. Fragments of identical size can be identified between the Cf0 phage clones and the YACs harboring VFNT Cherry DNA. Hcr9s represented by fragments of the phage clones ( $\Psi N L O A, \Psi N L O B, N L O D$, $N L O E)$ or YAC clone YV43b9 ( $\Psi N L V A)$ are indicated. In YV49d12, fusion of the insert with the right YAC vector arm occured within the genomic 3.0-kb BglII fragment representing $\Psi N L V A$ (Fig. 6), removing most of the sequence hybridizing to $C f-9$ probe 1 and altering the fragment size. On phage $0-27$, only a $3^{\prime}$ portion of $N L O C$ is present. Therefore, this gene is not represented by a fragment hybridizing to $C f-9$ probe 1 , which only covers 753 bp of the $5^{\prime}$ portion of the gene. Fragment marked by an asterisk present in both YV39d7 and YV49d12 maps to a region on the YAC contig with homology to $C f-9$ but outside the clustered $\mathrm{Hcr} 9 \mathrm{~s}$ (Fig. 6).
The following additional similarities and sequence identities were observed between the VFNT YAC contig and the two Cf0 phage contigs, which, together with the mapping data, strongly suggest that allelic DNA from both cultivars was compared.

(i) The insert of YAC V49d12 ends within $\Psi N L V A$, the Hcr9 corresponding to the 3.0-kb BglII fragment (Fig. 6). The total insert sequence of $171 \mathrm{bp}$ of an inverse PCR product from the right end of this YAC was identical only to $\Psi N L O A$, the $H c r 9$ in $\mathrm{CfO}$ that corresponds to the $3.0-\mathrm{kb} B g l \mathrm{II}$ fragment (Figs. 5 and 6). This sequence identity started from nucleotide position 415 in $\Psi N L O A$ and included a unique 2-bp deletion that results in a frameshift.

(ii) The four clustered $H c r 9 \mathrm{~s}$ on the VFNT YACs were contained within two adjacent BamHI fragments of 22 and 5.5 $\mathrm{kb}$ (Fig. 6). The 5.5-kb BamHI fragment was nonpolymorphic between Cf0, Cf9, and VFNT Cherry (Fig. 3; and data not shown). This fragment was contained in the second Cf0 phage contig (Fig. 6).

(iii) A 928-bp fragment was amplified from VFNT Cherry YACs YV49d12 and YV43b9 with the gene-specific primers NL159F and NL1070R based on the NLOE sequence. The sequence of this PCR product was identical to the corresponding region in $N L O E$.

(iv) PCR products of identical size $(3.0 \mathrm{~kb})$ were obtained with gene-specific primers spanning the intergenic region between $N L O D$ and $N L O E$ from genomic DNA of CfO and VFNT Cherry as well as from YACs YV49d12 and YV43b9 (Fig. 6). Approximately $500 \mathrm{bp}$ from both ends of these PCR products were analyzed, which confirmed the identity between the VFNT- and Cf0-derived sequences. Furthermore, digestion of these PCR products with BamHI produced two restriction fragments that had similar sizes when the two samples were compared, indicating a BamHI site conserved between VFNT Cherry and Cf0 (Fig. 6). These results suggest the presence of $H c r 9 \mathrm{~s}$ in VFNT Cherry at positions identical to $N L O D$ and $N L O E$ (NLVC and NLVD in Figure 6). Furthermore, the two pairs share the same transcriptional orientation.

Two non-overlapping Cf0 phage contigs were constructed (Fig. 6). As the physical proximity of the corresponding $\mathrm{Hcr} 9 \mathrm{~s}$ in the VFNT YAC contig suggested all five $N L H c r 9 \mathrm{~s}$ in CfO should be closely physically linked, we attempted to join the two contigs by a PCR fragment that overlapped the ends of both contigs. Oligonucleotides priming toward the right end of phage 0-327 (NL0C73R) and toward the left end of phage 0309 (RTR) were designed. Primers RTR and NL0C73R amplified a 4.5-kb PCR product (Fig. 6), specifically from genomic DNA of Cf0 and Cf9 but not from Cf4 or VFNT Cherry, indicating amplification from $L$. esculentum DNA distal to the introgressed segment in $\mathrm{Cf} 9$, where the $\mathrm{Cf} 4$ and Cf9 NILs differ (Figs. 1 and 2). This is consistent with the fragment representing $N L$ DNA. The sequence of the PCR product exhibited $100 \%$ identity with sequences obtained from the phage ends and enabled both contigs to be joined physically (Fig. 6).

\section{Polymorphic haplotypes of $N L$.}

Despite the apparent overall similarity of corresponding Hcr9s at $N L$ in L. esculentum VFNT Cherry, Cf0, and Cf9, detailed physical analysis suggests the number of $\operatorname{Hcr} 9 \mathrm{~s}$ at $N L$ in these lines is different. Significantly, no $\mathrm{Hcr} 9$ identical to 
NLOC could be detected at $N L$ in VFNT Cherry either by DNA gel blot analysis of the YAC clones or by PCR with gene-specific primers. Only four BglII fragments hybridizing to $C f-9$ probe 1 were present on the 27.4 -kb interval delimiting the $N L H c r 9$ cluster in VFNT and these correspond to $\Psi N L V A, N L V B, N L V C$, and $N L V D$ (Figs. 5 and 6). The sequence of $N L O C$ predicted it would be represented by a $4.7-\mathrm{kb}$ $B g l$ II fragment. On DNA gel blots hybridized with $C f-9$ probe 1 , one $B g l \mathrm{II}$ fragment of $5.0 \mathrm{~kb}$ was present in VFNT Cherry whereas two fragments of similar size were present in CfO. The presence of two similar sized fragments precluded a reliable scoring in the $\mathrm{F}_{2} \mathrm{PE}$ population. It is possible that this additional fragment represents $N L O C$, as the sequence $5^{\prime}$ of one of the $B g l$ II sites (GGCAGATCT) indicated possible C methylation (on the $\mathrm{CpTpG}$ of the complementary strand) that would affect $B g l I I$ cleavage. Sequence analysis revealed that cleavage of the next $B g l I I$ site would generate a fragment of $5.0 \mathrm{~kb}$. PCR with $N L O C$-specific primers gave no product with VFNT Cherry genomic DNA or the YACs YV39d7, YV43b9, and YV49d12 as templates. Additional polymorphism between the haplotypes was revealed in DNA gel blots hybridized with $C f$ - 9 probe 1 . A unique hybridizing BamHI fragment of $22 \mathrm{~kb}$ in VFNT Cherry was contained within the $N L$-YAC contig and was absent from Cf0, whereas two BamHI fragments of 13.6 and $15.2 \mathrm{~kb}$ (Fig. 3B) characteristic of the Cf0 version of $N L$ were absent in VFNT Cherry (data not shown). The physical position of these BamHI fragments is indicated in Figure 6.

Polymorphism at $N L$ was also observed between $\mathrm{Cf} 4$ and Cf0 (Fig. 3). A Cf4-specific, 8.5-kb BamHI fragment and a
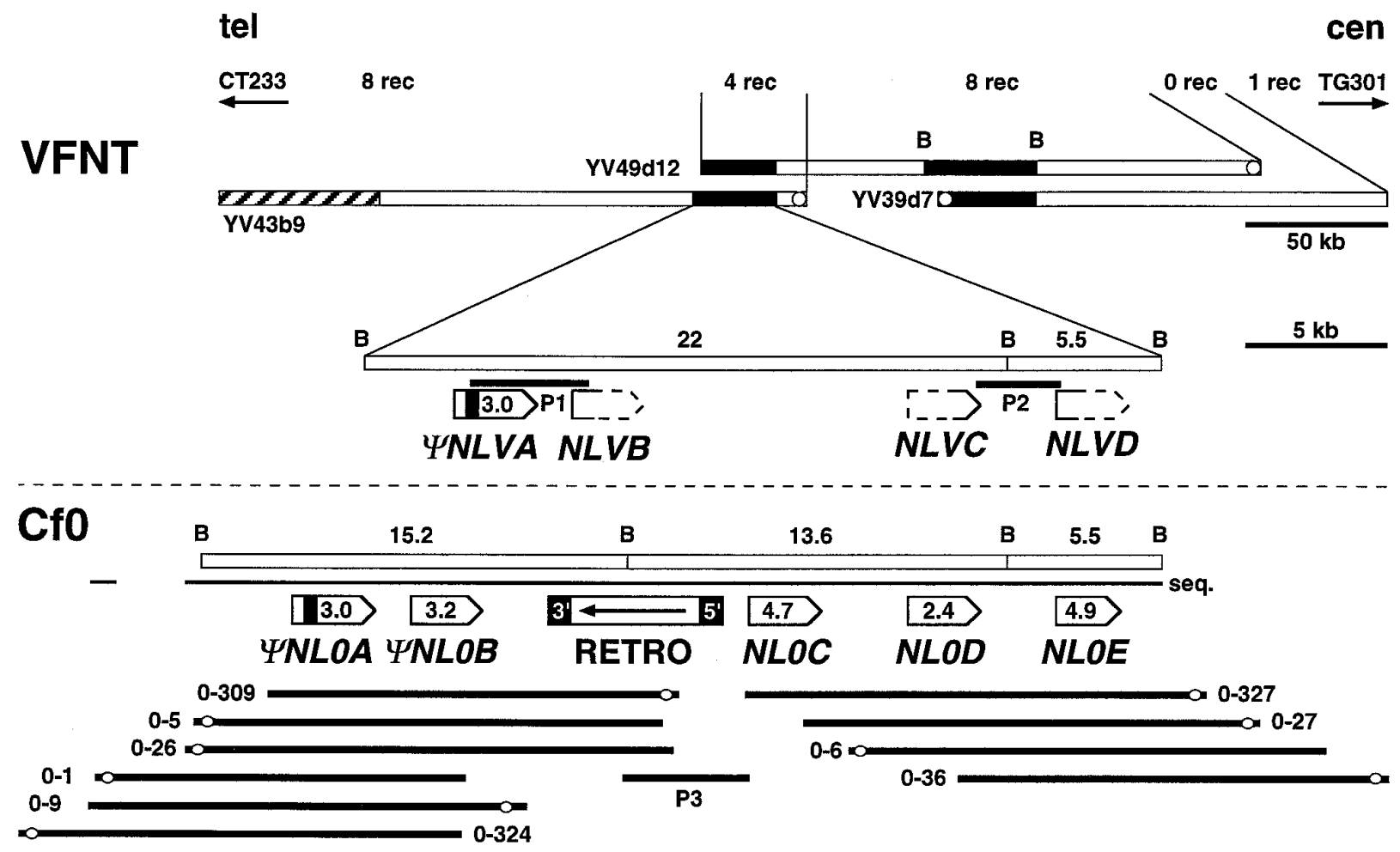

Fig. 6. Physical map of Northern Lights (NL). Physical maps of the $N L$ region of Lycopersicon esculentum VFNT Cherry and $L$. esculentum cv. Moneymaker (Cf0). VFNT: Insert sizes and positions of three overlapping yeast artificial chromosome (YAC) clones carrying VFNT Cherry genomic DNA (Bonnema et al. 1996) are indicated by three bars at top. Two regions delimited by BamHI (B) sites hybridizing to $C f-9$ probe 1 are indicated by black bars. Orientation of this YAC contig relative to the telomere (tel) and centromere (cen) has been determined by mapping of molecular markers derived from YAC ends (Bonnema et al. 1996). Left ends of YACs are marked by hollow circles. YV43b9 is a chimeric clone the extent of which is indicated by a hatched bar (Bonnema et al. 1996). Number of recombination events (rec) between molecular markers in this region identified within the $84 \mathrm{~F}_{2}$ plants of the $\mathrm{F}_{2} \mathrm{PEwag}$ population is also indicated. Position and transcriptional orientation of $\mathrm{Hcr} 9 \mathrm{~s}$ are shown by arrows. Numbers within arrows show corresponding genomic $B g l \mathrm{II}$ fragment sizes hybridizing to $C f-9$ probe 1 . Bam HI (B) fragments are indicated by hollow bars. A 5.5-kb BamHI fragment is present at $N L$ in both genotypes. The insert of YV49d12 ends within $\Psi N L V A$. The sequence of an 171-bp IPCR (inverse polymerase chain reaction) product from the right end of this YAC was identitical only to $\Psi N L O A$ (black boxes in $\Psi N L V A$, $\Psi N L O A$ ). From this information the transcriptional orientation of these $H c r 9 \mathrm{~s}$ and consequently their chromosomal polarity could be determined as shown. Transcriptional direction of the remaining $H c r 9$ genes of VFNT Cherry at $N L$ was deduced from PCR analysis. P1: PCR fragment of $4.2 \mathrm{~kb}$ amplified with $\Psi N L 0 A$ gene-specific primer NL0A552F in combination with NL0D491R on VFNT Cherry YACs. P2: PCR fragment of $3.0 \mathrm{~kb}$, amplified from genomic DNA of VFNT Cherry with NLOD and $N L O E$ gene-specific primers NL0D2505F and NL0E169R. Maximum extent of the $N L V$ cluster consisting of $\Psi N L V A$ to $N L V D$ is $27.4 \mathrm{~kb}$, as determined by gel blot analysis. No additional homology to $C f-9$ could be detected in the approximately $100 \mathrm{~kb}$ of the nonchimeric portion of YAC contig distal to the $N L V$ cluster. Cf0: Two phage contigs carrying L. esculentum cv. Moneymaker Cf0 genomic DNA. P3 indicates position of a PCR fragment physically joining the phage contigs that was amplified with primers RTR and NL0C73R. Sequenced regions are indicated (seq.). Insert sizes and relative position of phage clones are shown by bars. Hollow circles indicate insert end facing the left phage arm. RETRO indicates a sequence with features of a retrotransposon; arrow indicates transcriptional orientation of an intact open reading frame encoding a peptide with homology to reverse transcriptase. $5^{\prime}$ and $3^{\prime}$ denote long terminal repeats. Size of the $N L O$ cluster is $29.7 \mathrm{~kb}$ (from the ATG transcriptional start site of $\Psi N L O A$ to the stop codon of $N L O E$ ). 
$B g l \mathrm{II}$ fragment of $5.9 \mathrm{~kb}$ hybridizing to $C f-9$ probe 1 were localized distal to $\mathrm{CP} 46$ in the $\mathrm{F}_{3} \mathrm{FT} 4$ population (Fig. 3). The 5.9-kb $B g l I I$ fragment, and an additional $B g l I I$ fragment of 2.6 $\mathrm{kb}$ originating from $\mathrm{Cf} 4$, cosegregated with $\mathrm{CP} 46$ in the $\mathrm{F}_{2} \mathrm{P} 4 \mathrm{rec}$ population. It is therefore possible that these fragments represent the $\mathrm{Cf} 4$ version of $N L$ (Fig. 3). The Cf4 line has been generated by introgression of the $C f$ - 4 gene from $L$. hirsutum into the Cf0 line (Tigchelaar 1984). As Cf4 carries a $N L$ haplotype different from the parental line $\mathrm{Cf0}$, the introgressed segment of $L$. hirsutum DNA in the Cf4 line probably constitutes $N L$. This is consistent with an earlier report that concluded that the $L$. hirsutum introgression extends distal to marker $721 \mathrm{AR}$ in Cf4 (Balint-Kurti et al. 1995; Figs. 1 and 2).

PCR with NLOE gene-specific primers NL159F and NL1070R for the gene amplified products of identical size (928 bp) from VFNT Cherry, Cf0, and Cf4. The sequences of the VFNT Cherry- and CfO-derived PCR products were identical, whereas three nucleotides were different in the sequence obtained from the Cf4 line, indicating that this gene is highly conserved between different Lycopersicon spp.

Two $B g l$ II fragments of L. pennellii DNA of 5.1 and $5.5 \mathrm{~kb}$ that hybridized to $C f-9$ probe 1 mapped distal to CP46 in the $\mathrm{F}_{2} \mathrm{PE}$ population. Furthermore, an $L$. pennellii-specific PCR product could be amplified with the primers GBF2 and HCR1282R, and cosegregated with the 5.5-kb $B g l$ II fragment. This primer combination gave a PCR product of approximately $1.3 \mathrm{~kb}$ when used on Cf0 or L. pennellii DNA and an additional specific product of approximately $1.1 \mathrm{~kb}$ when used with $L$. pennellii. As stated earlier, the $\mathrm{F}_{2} \mathrm{PE}$ population size was too small to establish allelism of $H c r 9$ loci between $L$. esculentum and L. pennellii. However, assuming synteny between the two species, these fragments are likely to represent $H c r 9$ s of an L. pennellii haplotype of $N L$.

\section{DISCUSSION}

The outcome of the interaction between Cladosporium fulvum and tomato depends largely on the ability of the host plant to recognize the presence of the fungus and to respond by the induction of appropriate defense responses. It is therefore assumed that the existence of fungal races that are able to escape the plant surveillance system imposes a selection pressure on the plant to evolve novel recognition specificities. Within the Hcr9 gene family multiple distinct recognition specificities are encoded. The mechanisms that govern the evolution of novel sequence variants and hence potentially novel specificities in this gene family are therefore of major interest. In an earlier analysis we discovered that Hcr 9 genes at the $C f-4 / 9$ locus are composed of a patchwork of sequence affiliations, suggesting that sequence stretches were exchanged between gene family members during evolution. The precise mechanisms involved are not known but the observed pattern is consistent with unequal crossing over or gene conversion events between different Hcr9s (Parniske et al. 1997). However, our analysis of the gene family also revealed that $\mathrm{Hcr} 9$ genes are also present outside the gene cluster at the $C f-4 / 9$ locus. This finding raised a number of interesting questions about their location, physical organization, and evolutionary relationship to $\mathrm{Hcr} 9 \mathrm{~s}$ at $M W$.

\section{Hcr9 genes are present at multiple loci on the short arm of tomato chromosome 1.}

To investigate the role of these additional family members in the evolution of sequence diversity, we started by mapping these $H c r 9$ s genetically and physically. These studies showed the Hcr 9 gene family is spatially restricted to the short arm of chromosome 1 , and organized in three major clusters of tandemly repeated genes $(N L, M W$, and $S C)$. Two additional loci carrying $H c r 9$ s have been identified. Within the $N L$ YAC contig an individual $\mathrm{Hcr} 9$ was physically separated by an interval of between 57 and $92 \mathrm{~kb}$ from the locus harboring four to five clustered $\mathrm{Hcr} 9 \mathrm{~s}$ (Fig. 6). Furthermore, fragments with homology to $C f-9$ map proximal to the $S C$ locus $(0.8$ and 10 in Figure 1), suggesting the presence of additional Hcr9s. It is likely that even more $H c r 9$ loci exist, because some fragments on genomic DNA gel blots hybridizing to $C f$ - 9 did not reveal scorable polymorphisms and could therefore not be localized genetically. Furthermore, a number of phage, cosmid, and YAC clones carrying Hcr9s have been isolated that could not be assembled into any of the established $S C, M W$, or $N L$ contigs. The extent of the physical contigs around the $N L, M W$, and $S C$ loci precludes these additional Hcr9s from being in close physical vicinity.

The Hcr 9 distribution pattern on one chromosome arm is intermediate in complexity when compared with the genomic organization of other $R$ gene families. The Rpml gene of Arabidopsis thaliana, probably the most extreme example, has no detectable homologue as defined by cross hybridization on DNA gel blots, and homology is completely missing from accessions not exhibiting the Rpml recognition specificity (Grant et al. 1995). The next level of complexity is exhibited by the $C f-2$ gene family of tomato and the Xa21 $R$ gene family of rice, which both occur in single, locally restricted clusters of homologous, tandemly repeated genes (Dixon et al. 1996, 1998; Song et al. 1997; Song et al. 1995). The Hcr9 gene family with its broader distribution on one chromosome arm represents the next level of complexity, together with the Dm3 locus of lettuce, which appears to carry multiple copies of $R$ gene homologues spread over several megabases (Anderson et al. 1996; Shen et al. 1998). The other extreme are $R$ gene families that are distributed over several chromosomes. For example, the homologous $L$ and $M$ genes of flax are unlinked (Anderson et al. 1997; Lawrence et al. 1995) and a probe with homology to the nucleotide-binding-site (NBS)-LRR class of $R$ genes (Van der Biezen and Jones 1998) hybridized with fragments mapping to three different chromosomes of maize (Collins et al. 1998). It will be interesting to analyze whether these differences in genomic organization correlate with detectable patterns of evolutionary relationships between family members.

When and how did this complex arrangement of the Hcr9 gene family evolve? As all $\mathrm{Hcr} 9$ s are probably derived from a common ancestral sequence, their evolution must have involved both duplication and translocation events. We analyzed and compared the spatial organization of $\mathrm{Hcr} 9 \mathrm{~s}$ in four $\mathrm{Ly}$ copersicon spp. The DNA originated from NILs carrying DNA segments from L. hirsutum (Cf4) or L. pimpinellifolium (Cf9) introgressed into the short arm of chromosome 1 of $L$. esculentum (Fig. 2) or from the species L. pennellii and L. esculentum. These four species represent a large proportion of the genetic divergence within the genus Lycopersicon. Several 
Hcr9 loci were detected in all of these species (Fig. 2). Allelism tests revealed the presence of $H c r 9$ genes at the $M W$ locus of $L$. esculentum, L. hirsutum, and $L$. pimpinellifolium. We have physically analyzed the $S C$ and $N L$ loci from $L$. esculentum. We identified $\mathrm{Hcr} 9 \mathrm{~s}$ representing candidate alleles of $S C$ from L. pimpinellifolium as well as in L. pennellii. At $N L$ candidate $H c r 9$ s have been identified in $L$. hirsutum and $L$. pennellii. The presence of $H c r 9$ clusters at similar positions in different Lycopersicon spp. indicates their syntenic organization within the genus. Large $\mathrm{Hcr} 9$ gene families are also present in other genera of the Solanaceae (Kooman-Gersmann et al. 1996). In Solanum tuberosum, three loci constituting $C f-9$ homologous sequences have been mapped to the short arm of chromosome 1 (Leister et al. 1996), suggesting a similar spatial distribution of gene family members in tomato and potato. Therefore, it is possible that the molecular events that led to Hcr 9 cluster amplification preceded not only speciation but also the divergence of different genera within the Solanaceae. A complex spatial distribution of $R$ gene homologues of the NBS-LRR class has been observed in the Graminaceae (Leister et al. 1998). In contrast to the apparent synteny observed for Hcr 9 loci between Solanaceous species, less conservation appears to exist at $R$ gene loci between otherwise highly syntenic cereal genomes.

\section{Conserved lipoxygenase fragments at the $S C$ and $M W$ loci suggest local $\mathrm{Hcr} 9$ duplication preceded translocation of tandem repeats.}

Sequence comparisons between $S C$ and $M W$ revealed their overall cluster organization is very similar, which allows important conclusions to be drawn regarding the steps that led to their evolution. In the intergenic region between $S C O A$ and $\psi S C O B$ a $L O x L$ fragment is present that exhibits near sequence identity to fragments found in six out of eight intergenic regions at $M W$ (Parniske et al. 1997). This LoxL fragment has previously been described as a remnant of the initial duplication event giving rise to tandemly arranged Hcr9 genes (Parniske et al. 1997). The finding of an identical fragment at $M W$ and $S C$ further substantiates this hypothesis and suggests that the multiplication of $\mathrm{Hcr} 9$ clusters occurred after a tandem repeat was formed at a progenitor locus.

One mechanism that could have given rise to multiple $\mathrm{Hcr} 9$ clusters is a (partial) duplication of the short arm of chromosome 1 mediated by a breakage/fusion cycle. Alternatively, transposons could have catalyzed the multiplication of $\mathrm{Hcr} 9$ clusters. For example, in maize, sequences flanked by Activator $(A c)$ elements can transpose as part of a macrotransposon (Ralston et al. 1989). It is therefore possible that $\mathrm{Hcr} 9 \mathrm{~s}$ were translocated due to their physical linkage to transposable elements. In both scenarios, depending on the position of the transposable elements relative to $\mathrm{Hcr} 9$ clusters, sequences flanking the progenitor $\mathrm{Hcr} 9$ locus would also have been duplicated. At the $5^{\prime}$ end of the $S C$ locus we found sequences with near identity to the lipoxygenase sequences at the $5^{\prime}$ end of the $C f-4 / 9$ locus $(M W)$, indicating that sequences outside the $H c r 9$ cluster have been amplified. However, in a study toward a physical map of the short arm of tomato chromosome 1, Bonnema et al. (1997) employed RFLP markers and probes derived from YAC ends, several of which hybridized to single copy sequences. Most significantly, several probes derived from ends of YACs that carried $\mathrm{Hcr} 9 \mathrm{~s}$ detected single- copy sequences ( $\mathrm{G}$. Bonnema, unpublished). These observations make larger chromosomal duplications less likely and favor a model in which Hcr9 clusters were duplicated as smaller fragments.

Other known transposed sequences are retrogenes and retropseudogenes. The mechanism of their transposition involves an RNA intermediate that acts as a template for reverse transcriptase, an enzyme ubiquitously present in higher eukaryotes. Typically, retrogenes exhibit features of RNA processing such as, for example, a reduced number of introns ( $\mathrm{Li}$ 1997). Only one intron has been identified in $C f-93^{\prime}$ of the $2.6-\mathrm{kb}$ coding region. It is therefore possible that a retroposition event took place during the evolution of the gene family. However, all Hcr9 genes exhibit open reading frames that are not interrupted by introns., If the low intron number of $\mathrm{Hcr} 9 \mathrm{~s}$ is indeed due to a retroposition event, it must necessarily have preceded the amplification of the gene family. Furthermore, retroposition does not explain the accumulation of $\mathrm{Hcr} 9 \mathrm{~s}$ on one chromosome arm and is incompatible with the observation of sequence conservation outside the predicted transcribed regions.

\section{Resistance genes at other $\mathrm{Hcr} 9$ loci.}

The discovery of additional $C f$ specificities encoded by $H c r 9$ s within the $C f-9$ cluster (Parniske et al. 1997) demonstrates the capacity to develop novel $\mathrm{Hcr} 9$ recognition specificities. The resistance phenotypes of Cf9 lines carrying mutant versions of $C f-9$ suggested the presence of additional recognition specificities on the introgressed DNA segment that carries $C f-9$ (Hammond-Kosack et al. 1994b; Laugé et al. 1998). These phenotypes cannot be fully mimicked by combinations of $H c r 9$ s from the $C f-9$ cluster (Hammond-Kosack et al. 1994b; Parniske et al. 1997). Although the expression level of $H c r 9$ genes at $S C$ and $N L$ has not yet been analyzed, some $H c r 9$ s residing at $N L$ and $S C$ contain intact open reading frames, suggesting that they are active genes. It is possible that additional resistance specificities are encoded at Hcr9 loci other than $M W$. The availability of large germplasm collections, both of the fungus and the plant, continues to be useful for the identification of novel Cf/Avr combinations (Laugé et al. 1998). The possibility to deliver candidate Avr-gene products by expression from a virus vector (Thomas et al. 1997) is a powerful tool for the discovery of novel matching Avr/Hcr 9 pairs, which will enable us to further understand the molecular basis of pathogen perception by plants.

\section{MATERIALS AND METHODS}

\section{Plant material and mapping populations.}

Genetic distances were calculated with data from the following seven mapping populations with the program JoinMap (Stam 1993):

$\mathrm{F}_{2} \mathrm{EP}$ : 42 plants that had been maintained by propagation from an $\mathrm{F}_{2}$ population of the cross $L$. esculentum VF36-Tm $2 a$ $\times$ L. pennellii LA716, a subset of the population used to generate the tomato RFLP map (Tanksley et al. 1992).

$\mathrm{F}_{2}$ EPwag: 84 plants of an $\mathrm{F}_{2}$ population of the cross L. esculentum cv. Allround $\times$ L. pennellii LA716 (Odinot et al. 1992).

$\mathrm{F}_{2} \mathrm{P} 9 \mathrm{~S}$ : An $\mathrm{F}_{2}$ population of 62 plants of the cross $\mathrm{Cf9} \times L$. pennellii LA716. Plants were tested for the presence of $C f-9$ 
by injection with AVR9 containing intercellular washing fluids from $\mathrm{Cf0}$ leaves infected with $C$. fulvum race 5. Nonresponding plants (i.e., lacking $C f$-9) were selected for DNA preparations.

$\mathrm{F}_{2}$ P9rec: An $\mathrm{F}_{2}$ population of 41 recombinant plants from a total of $626 \mathrm{~F}_{2}$ plants of a Cf9 $\times$ L. pennellii LA716 cross screened for recombination events between TG236 and CP46 (Thomas et al. 1995).

$\mathrm{F}_{2}$ P4rec: A population of 8 recombinant plants from a total of $170 \mathrm{~F}_{2}$ plants from a $\mathrm{Cf} 4 \times \mathrm{L}$. pennellii LA716 cross screened for recombination events between TG236 and CP46. The strategy to identify recombinants was similar for both the $\mathrm{F}_{2} \mathrm{P} 9 \mathrm{rec}$ and the $\mathrm{F}_{2} \mathrm{P} 4 \mathrm{rec}$ populations. Plants homozygous for the L. pennellii allele of CP46 or TG236 were selected. Recombinants were identified by analyzing those plants for heterozygosity at TG236 or CP46 respectively. Plants homozygous for the non-L. pennellii allele of either flanking marker were not included in this analysis. Therefore, this population contains only a subset of the possible recombinants in the CP46/TG236 interval.

$\mathrm{F}_{3} \mathrm{FT} 4$ and $\mathrm{F}_{3} \mathrm{FT}$ 9: $\mathrm{F}_{2}$ populations of crosses between $\mathrm{Cf} 4$ or Cf9 and the disease susceptible line Cf0 FT33, which carries the maize transposon Dissociaton $(D s)$ expressing the uidA $(\beta$ glucuronidase [GUS]) gene at FT33 (Rommens et al. 1992), were screened for recombination events between the markers FT33 and CP46, which flank the $C f-4 / 9$ locus. From $331 \mathrm{~F}_{2}$ plants of the cross $\mathrm{Cf} 9 \times \mathrm{Cf0}$ FT33 $\left(\mathrm{F}_{2} \mathrm{FT} 9\right), 76$ progeny homozygous for the Cf9 allele of FT33, (i.e., $\mathrm{GUS}^{-}$), were screened for heterozygosity at the distal marker CP46 by DNA gel blot analysis and four recombinants (percentage recombination $3.9 \pm 1.6 \%$ ) were identified. From $560 \mathrm{~F}_{2}$ plants of the cross Cf4 $\times$ Cf0 FT33 $\left(\mathrm{F}_{2} \mathrm{FT} 4\right), 102$ plants homozygous for the $\mathrm{Cf} 4$ allele of FT33 were screened for heterozygosity at CP46 and seven recombinants (percentage recombination 3.4 $\pm 1.3 \%$ ) were identified. The $102 \mathrm{~F}_{2} \mathrm{FT} 4$ plants were also screened for recombination between CP46 and 721AR, and one recombinant was isolated (rec. 67). Plants homozygous for recombinant chromosomes were selected in the $\mathrm{F}_{3}$.

\section{Probes and primers.}

$C f-9$ probe 1 consists of 753 bp of the $5^{\prime}$ portion of the $C f-9$ gene from an XhoI site $160 \mathrm{bp} \mathrm{5^{ \prime }}$ of the ATG translational start codon to an SstI site located 593 bp 3' of the ATG (Jones et al. 1994). The RFLP marker 721AR has been described previously (Thomas et al. 1994). Cleaved amplified polymorphic sequence (CAPS) versions of RFLP markers CP46 (Gebhardt et al. 1991) and TG236 (Tanksley et al. 1992) were used as described previously (Balint-Kurti et al. 1994). The sequence of the gene-specific primers used for PCR amplification of NLOE were as follows: NL159F GACATAACAGACCAA GAG and NL1070R GAATTCTTAGGCTTGGCG; and for NLOC: NLA1RTTCATTCTCGTAGTAATC and NLA2F TAACAATTTGGAGGGAACG. Primers used to PCR amplify a $\psi S C O B$ specific fragment were as follows: GBF2 GTGCAGAAATGGATTGTG and GBR4 CACTATGTTGGT GAGATTCC. Primers to amplify the $L$. pennellii specific Hcr 9 product were as follows: GBF2 in combination with HCR1282R GTTTTGGACTTGAACTCTTG.

Primers NLOC73R CTTGATCTTCGGGGCACAAATG AC and RTR GTAACCAGCAATAAACTTTCGATAATAG TTAGCC were used to amplify a fragment from genomic
DNA that physically connected the two Cf0 phage contigs at $N L$. This fragment was amplified with a $P w o / T a q$ mixture for high fidelity PCR (Boehringer, Mannheim, Germany). Primers to amplify P1 (Fig, 6) were as follows: NL0A552F CATAT GGGCCTCACAATTTTGAACG in combination with NL0D491R CTAAGCCCATATGGATAATCAGTCGAGG. P2 was amplified with NL0D2505F GTAAAATTGGAACA CATCATTAG in combination with NL0E169R GACTGGA TATTCTCTTGGTCTG .

\section{Genomic libraries.}

The YAC clones are derived from libraries of VFNT Cherry or Cf4 genomic DNA (Bonnema et al. 1996). Cosmids were isolated from genomic libraries of tomato lines harboring the $C f$-2 and $C f$-9 genes (Dixon et al. 1996) or the $C f-4$ and $C f-5$ genes (Thomas et al. 1997). A library of partially MboIdigested genomic DNA of L. esculentum cv. Moneymaker (Cf0) was constructed in the lambda phage replacement vector EMBL3 (Stratagene, La Jolla, CA).

\section{ACKNOWLEDGMENTS}

We thank Noel Ellis for helpful discussions, David Baker and Patrick Bovill for assistance in the operation and maintenance of the sequencing equipment, Erik van der Biezen and Catherine Golstein for critical reading of the manuscript, and Sara Perkins for plant care and greenhouse maintenance. B. B. H. W. received a student grant (SU UDL3121) from the Danish government. M. P. was supported by fellowships of the European Molecular Biology Organisation (EMBO) and the European Community. Research at the Sainsbury Laboratory is funded by the Gatsby Charitable Foundation.

\section{LITERATURE CITED}

Anderson, P. A., Lawrence, G. J., Morrish, B. C., Ayliffe, M. A., Finnegan, E. J., and Ellis, J. G. 1997. Inactivation of the flax rust resistance gene $M$ associated with loss of a repeated unit within the leucine-rich repeat coding region. Plant Cell 9:641-651.

Anderson, P. A., Okubara, P. A., Arroyogarcia, R., Meyers, B. C., and Michelmore, R. W. 1996. Molecular analysis of irradiation-induced and spontaneous deletion mutants at a disease resistance locus in Lactuca sativa. Mol. Gen. Genet. 251:316-325.

Balint-Kurti, P. J., Dixon, M. S., Jones, D. A., Norcott, K. A., and Jones, J. D. G. 1994. RFLP linkage analysis of the $C f-4$ and $C f-9$ genes for resistance to Cladosporium fulvum in tomato. Theor. Appl. Genet. 88:691-700.

Balint-Kurti, P. J., Jones, D. A., and Jones, J. D. G. 1995. Integration of the classical and RFLP linkage maps of the short arm of tomato chromosome 1. Theor. Appl. Genet. 90:17-26.

Bonnema, G., Hontelez, J., Verkerk, R., Zhang, Y. Q., Van Daelen, R., Van Kammen, A., and Zabel, P. 1996. An improved method of partially digesting plant megabase DNA suitable for YAC cloning - application to the construction of a 5.5 genome equivalent YAC library of tomato. Plant J. 9:125-133.

Bonnema, G., Schipper, D., Van Heusden, S., Zabel, P., and Lindhout, P. 1997. Tomato chromosome 1: High resolution genetic and physical mapping of the short arm in an interspecific Lycopersicon esculentum x L. peruvianum cross. Mol. Gen. Genet. 253:455-462.

Botella, M. A., Coleman, M. J., Hughes, D. E., Nishimura, M. T., Jones, J. D. G., and Sommerville, S. C. 1997. Map positions of 47 Arabidopsis sequences with sequence similarity to disease resistance genes. Plant J. 12:1197-1211.

Collins, N. C., Webb, C. A., Seah, S., Ellis, J. G., Hulbert, S. H., and Pryor, A. 1998. The isolation and mapping of disease resistance gene analogs in maize. Mol. Plant-Microbe Interact. 11:968-978.

Dixon, M., Hatzixanthis, K., Jones, D. A., Harrison, K., and Jones, J. D. G. 1998. The tomato $C f-5$ disease resistance gene and six homologs show pronounced allelic variation in the leucine-rich repeat copy number. Plant Cell 10:1315-1326. 
Dixon, M. S., Jones, D. A., Keddie, J. S., Thomas, C. M., Harrison, K., and Jones, J. D. G. 1996. The tomato $C f$-2 disease resistance locus comprises 2 functional genes encoding leucine-rich repeat proteins. Cell 84:451-459.

Fray, R. G., and Grierson, D. 1993. Identification and genetic analysis of normal and mutant phytoene synthase genes of tomato by sequencing, complementation and cosuppression. Plant Mol. Biol. 22:589-602.

Gebhardt, C., Ritter, E., Barone, A., Debener, T., Walkemeier, B., Schachtschabel, U., Kaufmann, H., Thompson, R. D., Bonierbale, M. W., Ganal, M. W., Tanksley, S. D., and Salamini, F. 1991. RFLP maps of potato and their alignment with the homoeologous tomato genome. Theor. Appl. Genet. 83:49-57.

Grant, M. R., Godiard, L., Straube, E., Ashfield, T., Lewald, J., Sattler, A., Innes, R. W., and Dangl, J. L. 1995. Structure of the Arabidopsis Rpm1 gene enabling dual specificity disease resistance. Science 269: 843-846.

Hammond-Kosack, K. E., Harrison, K., and Jones, J. D. G. 1994a. Developmentally regulated cell death on expression of the fungal avirulence gene Avr9 in tomato seedlings carrying the disease resistance gene $C f-9$. Proc. Natl. Acad. Sci. USA 91:10445-10449.

Hammond-Kosack, K. E., Jones, D. A., and Jones, J. D. G. 1994b. Identification of two genes required in tomato for full $C f$-9-dependent resistance to Cladosporium fulvum. Plant Cell 6:361-374.

Hammond-Kosack, K. E., and Jones, J. D. G. 1997. Plant disease resistance genes. Annu. Rev. Plant Physiol. Plant Mol. Biol. 48:575-607.

Jones, D. A., Dickinson, M. J., Balint-Kurti, P. J., Dixon, M. S., and Jones, J. D. G. 1993. Two complex resistance loci revealed in tomato by classical and RFLP mapping of the $C f-2, C f-4, C f-5$, and $C f-9$ genes for resistance to Cladosporium fulvum. Mol. Plant-Microbe Interact. 6:348-357.

Jones, D. A., Thomas, C. M., Hammond-Kosack, K. E., Balint-Kurti, P. J., and Jones, J. D. G. 1994. Isolation of the tomato $C f-9$ gene for resistance to Cladosporium fulvum by transposon tagging. Science 266 : 789-793.

Joosten, M. H. A. J., Cozijnsen, T. J., and De Wit, P. J. G. M. 1994. Host-resistance to a fungal tomato pathogen lost by a single base-pair change in an avirulence gene. Nature 367:384-386.

Kerr, E. A., and Bailey, D. A. 1964. Resistance to Cladosporium fulvum Cke obtained from wild species of tomato. Can. J. Bot. 42:1541-1554.

Kobe, B., and Deisenhofer, J. 1995. A structural basis of the interactions between leucine-rich repeats and protein ligands. Nature 374:183-186.

Kooman-Gersmann, M., Honee, G., Bonnema, G., and De Wit, P. J. G. M. 1996. A high affinity binding site for the AVR9 peptide elicitor of Cladosporium fulvum is present on plasma membranes of tomato and other solanaceous plants. Plant Cell 8:929-938.

Laugé, R., Dmitriev, A. P., Joosten, M. H. A. J., and De Wit, P. J. G. M. 1998. Additional resistance gene(s) against Cladosporium fulvum present on the $C f-9$ introgression segment are associated with strong PR protein accumulation. Mol. Plant-Microbe Interact. 11:301-308.

Lawrence, G. J., Finnegan, E. J., Ayliffe, M. A., and Ellis, J. G. 1995. The $L_{6}$ gene for flax rust resistance is related to the Arabidopsis bacterial resistance gene Rps 2 and the tobacco viral resistance gene $N$. Plant Cell 7:1195-1206.

Leister, D., Ballvora, A., Salamini, F., and Gebhardt, C. 1996. A PCRbased approach for isolating pathogen resistance genes from potato with potential for wide application in plants. Nat. Genet. 14:421-429.

Leister, D., Kurth, J., Laurie, D. A., Yano, M., Sasaki, T., Devos, K., Graner, A., and Schulze-Lefert, P. 1998. Rapid reorganization of resistance gene homologues in cereal genomes. Proc. Natl. Acad. Sci. USA 95:370-375.

Li, W. H. 1997. Molecular Evolution. Sinauer Associates, Sunderland, MA.

Odinot, P., Pet, G., and Lindhout, P. 1992. An $\mathrm{F}_{2}$ between Lycopersicon esculentum cv Allround and $L$. pennellii for mapping studies. Tomato Genet. Coop. Rep. 42:27-29.

Parniske, M., Hammond-Kosack, K. E., Golstein, C., Thomas, C. M., Jones, D. A., Harrison, K., Wulff, B. B. H., and Jones, J. D. G. 1997. Novel disease resistance specificities result from sequence exchange between tandemly repeated genes at the $C f-4 / 9$ locus of tomato. Cell 91:821-832.
Ralston, E., English, J., and Dooner, H. K. 1989. Chromosome-breaking structure in maize involving a fractured $A c$ element. Proc. Natl. Acad. Sci. USA 86:9451-9455.

Rommens, C. M. T., Rudenko, G. N., Dijkwel, P. P., Van Haaren, M. J. J., Ouwerkerk, P. B. F., Blok, K. M., Nijkamp, H. J. J., and Hille, J. 1992. Characterization of the Ac/Ds behavior in transgenic tomato plants using plasmid rescue. Plant Mol. Biol. 20:61-70.

Salmeron, J. M., Oldroyd, G., Rommens, C., Scofield, S. R., Kim, H. S., Lavelle, D. T., Dahlbeck, D., and Staskawicz, B. J. 1996. Tomato Prf is a member of the leucine-rich repeat class of plant disease resistance genes and lies embedded within the Pto kinase gene cluster. Cell 86: 123-133.

Scofield, S. R., Tobias, C. M., Rathjen, J. P., Chang, J. H., Lavelle, D. T., Michelmore, R. W., and Staskawicz, B. J. 1996. Molecular basis of gene-for-gene specificity in bacterial speck disease of tomato. Science 274:2063-2065.

Shen, K. A., Meyers, B. C., Islam-Faridi, M. N., Chin, D. B., Stelly, D. M., and Michelmore, R. W. 1998. Resistance gene candidates identified by PCR with degenerate oligonucleotide primers map to clusters of resistance genes in lettuce. Mol. Plant-Microbe Interact. 11:815823

Simons, G., Groenendijk, J., Wijbrandi, J., Reijans, M., Groenen, J., Diergaarde, P., Van der Lee, T., Bleeker, M., Onstenk, J., De Both, M., Haring, M., Mes, J., Cornelissen, B., Zabeau, M., and Vos, P. 1998. Dissection of the Fusarium I2 gene cluster in tomato reveals six homologs and one active gene copy. Plant Cell 10:1055-1068.

Song, W. Y., Pi, L. Y., Wang, G. L., Gardner, J., Holsten, T., and Ronald, P. C. 1997. Evolution of the rice Xa21 disease resistance gene family. Plant Cell 9:1279-1287.

Song, W. Y., Wang, G. L., Chen, L. L., Kim, H. S., Pi, L. Y., Holsten, T., Gardner, J., Wang, B., Zhai, W. X., Zhu, L. H., Fauquet, C., and Ronald, P. 1995. A receptor kinase-like protein encoded by the rice disease resistance gene, Xa21. Science 270:1804-1806.

Stam, P. 1993. Construction of integrated genetic linkage maps by means of a new computer package - JoinMap. Plant J. 3:739-744.

Tang, X. Y., Frederick, R. D., Zhou, J. M., Halterman, D. A., Jia, Y. L., and Martin, G. B. 1996. Initiation of plant-disease resistance by physical interaction of avrPto and Pto kinase. Science 274:2060 2063.

Tanksley, S. D., Ganal, M. W., Prince, J. P., Devicente, M. C., Bonierbale, M. W., Broun, P., Fulton, T. M., Giovannoni, J. J., Grandillo, S., Martin, G. B., Messeguer, R., Miller, J. C., Miller, L., Paterson, A. H., Pineda, O., Roder, M. S., Wing, R. A., Wu, W., and Young, N. D. 1992. High-density molecular linkage maps of the tomato and potato genomes. Genetics 132:1141-1160.

Thomas, C. M., Jones, D. A., English, J. J., Carroll, B. J., Bennetzen, J. L., Harrison, K., Burbidge, A., Bishop, G. J., and Jones, J. D. G. 1994 Analysis of the chromosomal distribution of transposon-carrying TDNAs in tomato using the inverse polymerase chain reaction. Mol. Gen. Genet. 242:573-585.

Thomas, C. M., Jones, D. A., Parniske, M., Harrison, K., Balint-Kurti, P. J., Hatzixanthis, K., and Jones, J. D. G. 1997. Characterization of the tomato $C f-4$ gene for resistance to Cladosporium fulvum identifies sequences that determine recognitional specificity in Cf-4 and Cf-9. Plant Cell 9:2209-2224.

Thomas, C. M., Vos, P., Zabeau, M., Jones, D. A., Norcott, K. A., Chadwick, B. P., and Jones, J. D. G. 1995. Identification of amplified restriction fragment polymorphism (AFLP) markers tightly linked to the tomato $C f-9$ gene for resistance to Cladosporium fulvum. Plant J. 8:785-794.

Tigchelaar, E. C. 1984. Collections of isogenic tomato stocks. Tomato Genet. Coop. Rep. 34:55-57.

Van der Biezen, E. A., and Jones, J. D. G. 1998. The NB-ARC domain: A novel signalling motif shared by plant resistance gene products and regulators of cell death in animals. Curr. Biol. 8:R226-R227.

van Kan, J. A. L., van den Ackerveken, G. F. J. M., and de Wit, P. J. G. M. 1991. Cloning and characterization of cDNA of avirulence gene avr9 of the fungal pathogen Cladosporium fulvum, causal agent of tomato leaf mold. Mol. Plant-Microbe Interact. 4:52-59. 